\title{
Forensic Interviewing Techniques in Child Sexual Abuse Allegations: Implications for the South African Context
}

\author{
Selelo Frank Rapholo ${ }^{1} \&$ Jabulani Calvin Makhubele ${ }^{1}$ \\ ${ }^{1}$ School of Social Sciences, University of Limpopo, Sovenga, South Africa \\ Correspondence: Dr. SF Rapholo, School of Social Sciences, University of Limpopo, Private Bag X1106, Sovenga, \\ South Africa.Tel: 27-15- 268-3876. E-mail: Frank.Rapholo@ul.ac.za
}

Received: February 16, 2019 Accepted: April 10, 2019 Online Published: April 28, 2019

doi:10.5539/gjhs.v11n6p53

URL: https://doi.org/10.5539/gjhs.v11n6p53

\begin{abstract}
This paper aims to examine forensic interviewing techniques during child sexual abuse allegations using South African lenses. Forensic Social Work education and practice in South Africa is emerging as it has been adopted from the United States of America. There are currently no guidelines for forensic social workers to inform the assessment of children who are alleged to be sexually abused which are in a South African context. For the protection of children, skillful forensic interviews must be conducted for perpetrators of child sexual abuse to be convicted. Forensic interviews help in eliciting accurate and complete report from the alleged child victim to determine if the child has been sexually abused and if so, by whom. The ecosystems theory is used to guide this paper. An extensive literature review was conducted to zoom into systems in South Africa which influence the effectiveness of the forensic interviewing techniques useful to facilitate the disclosure of sexual abuse amongst children.
\end{abstract}

Keywords: child sexual abuse, forensic interviews, forensic social work, South Africa

\section{Introduction and Background}

Child sexual abuse (CSA) is an alarming social and health problem globally. South Africa in particular, has in the past encountered lot of incidents of CSA and such were not reported due to various reasons. This has left children vulnerable for many years. According to the South African Police Service (SAPS) crime stat 2016/17, the reported sexual offences against children in South Africa were 49,660. For the financial year 2017/18, 50,108 sexual offences cases against children were reported. Of these sexual offences for $2017 / 18$, rape made 40,035 , sexual assault 6,786, attempted sexual offence 2, 066 and contact sexual offences 1,221 . One can note that there is a slight increase of 0.448 cases which were reported to SAPS between the years 2016/17 and 2017/18. These statistics in South Africa are unsettling and this leads to the future re-victimization of children. Klein (2010) postulates that CSA in the past, was not an acceptable topic for public conversation and that has rendered children reluctant to disclose their sexual abuse experiences.

The problem with the phenomenon of child sexual abuse in South Africa and of course across the globe is the disclosure. The writer has observed from his practical experience as a Social Worker in the Limpopo Province of South Africa that children are socialised not to discuss any disconcerting intimate family life details to the public and such influence children not to talk abuse sexual abuse, when is has happened within the family. The disclosure of child sexual abuse is a process. It is sometimes accidental wherein the third party observes signs of genital or physical injury, the occurrence of pregnancy or diagnosis of sexually transmitted diseases (World Health Organization [WHO], 1999; Ferarra, 2002; Spies, 2012). With accidental disclosure, Spies (2012) avers that the intervention may be difficult because both the child and other family members may not be willing to reveal the secret. Children are therefore understandably reluctant to disclose information about abuse (Cronch et al., 2006). Many sexually abused children never disclose because they are silenced by threats, blame and bribery (Spies, 2006). Children in a perfect world, when they disclose sexual abuse, would be believed, protected and be assured that it was not their fault. Children who do so, would be assisted with counselling whilst the perpetrator be taken to task (Spies, 2006; Fouché, 2006). Unfortunately, this practice is not always the case. Habitually, children are not believed after they have disclosed sexual abuse, instead they are blamed for the consequences of the disclosure. For these reasons, forensic social work in South Africa has been adopted from the United States of America to facilitate the disclosure of CSA. For the forensic social worker to conduct forensic interviews, s/he must be skilled 
and competent enough to do so.

Forensic social workers in South Africa who assess children alleged to be sexually abused use a variety of interviewing techniques. Forensic interviews are aimed at eliciting complete and more accurate report from the child victim to determine if the child has been sexually abused or not or is in looming risk of abuse and, if so, by whom (American Professional Society on the Abuse of Children [APSAC], 2002). These interviews are also aimed at gathering facts regarding the incident that is being investigated (Poole \& Lamb, 1998; Müller, 2001; Fouché, 2006; Faller, 2007; Saywitz \& Comparo, 2009; APSAC, 2012). Spies (2006) maintains that these interviews help forensic social workers to get an account from a child in a developmentally sensitive, unbiased, independent and truth-seeking manner to support accurate and fair decision making in the criminal justice system. Due to scant training on forensic social work in South Africa, and shortage of well-structured programmes and guidelines, majority of forensic social workers conduct assessments on sexually abused children and testify in courts on this matter without proper qualifications or specialization in this field (Fouché, 2006, Kaliski, 2006). This can cause a dilemma, because if the professional that interviews the child is not equipped to perform this kind of interview, there may in the end simply not be enough evidence to prosecute someone. Wood and Garven (2000) postulate that this practice may results with false allegations which may put the family through unnecessary stress, contamination of facts, decreasing the child's credibility in court, and reducing the probability of conviction. To avoid these negative outcomes, professionals who conduct forensic interviews should be well trained on how to conduct such in order to facilitate the disclosure of CSA. Skillful forensic interviews in CSA cases are extremely important to ensure the protection of innocent individuals and the conviction of perpetrators. The writers are also of the view that forensic interviewing techniques used in this regards should continuously be examined more especially that they have been adopted from the context of the United States of America. This paper is therefore aimed at examining forensic interviewing techniques with child sexual abuse allegations in a South African context. The ecosystems theory is used in this paper to examine these techniques.

\section{Theoretical Framework Underpinning Forensic Interviewing in a South African context}

For the purpose of this paper, the ecosystems theory is used to understand the nature of child sexual abuse in South Africa and the socio-economic and cultural systems which influence its disclosure thereof. The ecosystems theory was found by the Russian Psychologist, namely, Urie Bronfenbrenner, in 1979. Visser and Moleko (2012) denote that for professionals to understand a particular situation, they should first observe the interaction and impact between systems at different levels. Systems perspectives are paramount to social work practice because they accentuate its social focus (Payne, 2005). Pragmatically, the profession of social work focuses on the people's social connections and relationships. Therefore, the ecosystems theory is commonly used in the social work fraternity today (Weyers, 2011) to study the relationship between clients and systems around them (Weyers, 2011; Colton et al., 2001). During the forensic interviews, practitioners should be watchful of traditional ways of understanding child development by focusing on the child's immediate settings and wider societal influences on how they develop (Smith et al., 2003; Spies, 2006). The environment within which children find themselves in, has an influence on the effectiveness of the interviewing techniques. Therefore, forensic social workers should use the ecosystems theory to guide them understand different practices in different settings (Franklin \& Jordan, 1999) and how they can have an influence during forensic interviews.

\section{Forensic Interviewing Techniques and Strategies}

In conducting forensic interviews, professionals need to be watchful on the dynamics which can impact the disclosure rate. Rapholo (2018) has established from his study on forensic social work in South Africa that culture, language of both the child and the interviewer, age of the child and types of questions asked to the child, have an influence on the effectiveness of interviewing techniques. In addition, Cronch et al. (2006) and Rapholo (2018) stated personal characteristics of the child and the interviewer to an influence on the rate of disclosing CSA during forensic interviews. When conducting forensic interviews, such should be taken into consideration. Some of the forensic techniques may appear to be very effective at eliciting detailed and accurate disclosures and others not. The discussion in this paper is on forensic interviewing techniques in the context of South Africa as follows:

\subsection{Cognitive Interviewing Technique}

The cognitive interview was developed by Geiselman and colleagues in the 1980s. From Rapholo's (2018) study which was conducted in South Africa, cognitive interviewing technique has been found to be very relevant during the first contact with the child. It was also found that cognitive interviewing is more relevant when interviewing older children as opposed to younger children. This validates what Cronch et al. (2006) avow that cognitive interviewing was developed for adult witnesses and victims. If this technique can be used appropriately with the right age group of sexually abuse children, more desired results can be borne. Cognitive interviewing technique is 
more relevant to help children to recall of events (APSAC, 2002; Faller, 2003; Hayes \& Delamothe, 1997; Holliday, 2003; Cronch et al., 2006; Rapholo, 2018). Rapholo has established that cognitive interviewing helps the interviewer to establish the cognitive development of the child and to select the most appropriate interviewing technique which will enable the child to recall and disclose abuse if it had happened. The forensic social worker from Rapholo's (2018) study has indicated that this technique is the most effective in making children recall the previous events and that in most cases children disclose the possibility of abuse.

Categorically, Aldridge (1999); Cronch et al. (2006); Faller (2003); and Holliday, (2003) outline that cognitive interviewing technique has four retrieval mnemonics, namely:

- Mentally reconstructing the event, i.e., mental context reinstatement

- Reporting everything, regardless of perceived importance.

- Recalling the event in different sequences.

- Recalling the information from different views and perspectives.

Hershkowitz et al. (2006) support the above that the mental context reinstatement is a useful component of the cognitive interview compared to physical context reinstatement because the child is taken back to the crime scene. In order for mental context reinstatement to be useful, Poole and Lamb (1998) propose that the structure of the cognitive interview a sequence of four stages:

- Open-ended narration.

- The probing stage, during which the interviewer guides the witness to exhaust the contents of memory.

- A review stage, during which the interviewer checks the accuracy of notes about the interview and provides additional opportunities to recall.

- The closing.

Practically, the writers support the background of mental context reinstatement technique application, that, it helps mostly after the child has disclosed possible sexual abuse verbally, to ask him or her:

- To recognize any event that s/he may remember clearly;

- To make a picture of the things which happen; and

- To close eyes, make a mental picture of the alleged sexual abuse happenings and report anything that comes to mind (free narrative is allowed);

Immediately after the process has been followed, follow up questions directed to the abuse should be asked. Fouche (2007) concurs that children are more likely to remember clearly if this process is followed.

\subsection{Allegation Blind Interviews}

Allegation blind interviews imply that the interviewer assesses the child without prior knowledge of sexual abuse allegation (Cronch et al., 2006). The interview in this instance has only a limited knowledge to the child's age and gender prior to the interviews. Rapholo (2018) has established in South Africa that forensic social workers prefer to use blind assessment interviews than informed allegation interviews, however, the age of the child determines the use of either of the two. Blind assessment interviews increase the likelihood of more disclosure rates than informed allegation interviews (Cronch et al., 2006; Rapholo, 2018). Forensic social workers in South Africa have stated that informed allegations interviews are effective with very young children than older children and that their disadvantages are that they are leading, suggesting and subjective. This is supported by Poole and Lamb (1998) who postulate that blind interviews should be conducted by highly trained and competent interviewers who would avoid them with younger children. In the blind assessment interviews, the forensic interviewer possesses no knowledge of the perpetrator prior to the interviews. Rapholo states that even collaterals should not be interviewed prior to the assessment of the victim child. In the execution of this technique, there is totally no information about the allegation. However, APSAC (2002) argues that prior information about the allegation maybe useful in orientation the forensic social worker and clarifying the child's statement. In South Africa, it was established the conducting the interviews with the background of the allegation more especially with older children is more likely to cause the interviewer to be biased or suggestive. This validates Cronch et al.'s (2006) study on the examination of forensic interviewing techniques in the United States of America context that prior knowledge of the alleged sexual offence increases biasness to interviewer who would also ask leading and more suggestive questions. Considering the above discussion, forensic interviews should be blind allegation wherever possible. However, when assessing children below the age of four years, informed allegation interviews can be used. The writers 
advice that informed allegation interviews should be used after pre-forensic interviews when the forensic social worker has established the developmental level of the child. Rapholo (2018) has established that the forensic social worker should always establish the developmental level of the child when structuring his or her forensic interviewing questions. It was established that very young children provide less details due to their language skills. However, the forensic social worker should always take a non-judgemental, objective and neutral stance towards the interview (APSAC, 2002; Bruck \& Ceci, 1995; Carnes, 2000; Cronch et al., 2006; Rapholo, 2018; Saywitz et al., 2002).

\subsection{Open-Ended Questions}

Bull (2003a), Davies et al. (2000), Craig et al. (1999), Cronch et al. (2006), Faller (1993), Hershkowitz (2001), Lamb et al. (2000) and Orbach et al. (2000) avow that open-ended questions result with more detailed and accurate information pertaining to the alleged sexual offence than any other types of questions. However, forensic social workers in South Africa from Cronch et al. (2006) and Rapholo's (2018) studies have postulated that open ended questions are highly commendable when interviewing school-aged children and adolescents. It is therefore imperative that the forensic social worker establish the age of the child when structuring the types of questions. Fouche (2007) and Aldridge and Cameron (1999) define open-ended questions as questions as those that invite a broad reply and which cannot be answered simply by a "yes", "no", or other brief one-phrase reply. These questions usually start with what, when, who, where and how (Aldridge \& Cameron, 1999; Bull, 2003a; Faller, 2003; Lamb et al., 2000; Spies, 2006; Rapholo,2018). Hershkowitz (2001) holds a different view that open ended questions should be encouraged in all phases of the interview regardless of the age of the child. Rapholo (2018) and Spies (2012) conclude that open ended questions are more effective to elicit detailed facts on the possibility of CSA. However, these authors state that the age and/or the developmental level of the child should be taken into consideration at all times. Open ended questions help elicit credible information as they allow children to talk to the interviewer from his or her time of reference.

\subsection{Truth-Lie Discussions or Competency Assessment}

The aim of this technique is to help children differentiate between the truth and a lie. Cronch et al. (2006) aver that children's understanding of the difference between the "truth" and a "lie" should be assessed during the pre-forensic interviews (first contact), just before beginning the abuse-focused questioning. By so doing, the children's competency will be demonstrated and such will also increase the credibility of their statements in the criminal court (APSAC, 2002; Huffman et al., 1999; Cronch, 2006). Rapholo (2018) echoes that there are currently no guidelines and/or standard procedure on the use of true-lie discussions in South Africa and that even protocols which are used during forensic assessments do not include this technique. However, this is the most important technique as it helps children to know the implications of telling a lie more especially for court proceedings. Children should be asked if they have ever told a lie and if so, what the consequences were (Orbach et al., 2000; Spies, 2006). According to APSAC (2002)), the interviewer should test children's understanding of the truth and a lie by using examples ("Tell me a lie about this chair"). It is also imperative that the interviewer accentuates to the child the essence of telling the truth (Starks \& Samuel, 2002; Kuehnle, 1996). This technique also plays a crucial role during the rapport establishment stage (Rapholo, 2018; Smith, 2014). The forensic social worker should obtain the verbal agreement from the victim child to tell the truth throughout the interview (Huffman et al., 1999; Talwar et al., 2002). Fouche (2007) supports this by stating that every witness in the South African jurisdiction must undergo a competency examination before giving their testimony. The Criminal Procedure Act no. 51 of 1977 (SA, 1977) has a clause which states that children under the age of 14 will not be sworn in, rather a competency examination is done by the presiding officer. Forensic Social Workers are also summoned in South Africa to assess children's competency by using true-lie. The true-lie discussion technique increases the child's chances of telling the truth throughout the interviews (Connel, 2009). Thefore, it is very imperative that forensic social workers determine the child's comprehension about the difference between the truth and a lie, and the consequences of lying, before starting with the intensive forensic interviewing techniques. This technique should continuously be used in each session with the child to remind them about the importance of telling the truth. Rapholo (2018) states that children are likely to forget the discussions of the previous sessions.

Some forensic social workers in Rapholo's (2018) study in South Africa have indicated that age and culture have implications during the use of the true-lie discussion technique. In some cultures it is a sign of disrespect for children to tell an elderly person (the forensic interviewer in this instance) that it is a lie. To overcome this, Cronch et al. (2006) state that it is advisable to ask children questions on the moral implications of telling lies. For example, the interviewer can ask the child a question such as "What will happen if someone tells a lie". When conducting forensic interviews, it is always crucial that the interviewers assess the developmental level of the child. 
Spies (2012) concurs with this sentiment that a basic understanding of child development and developmental issues is an absolute necessity for anyone who works with child witnesses.

\subsection{Touch Survey}

The systematic Touch Survey has been found by Sandra Hewitt in the early 1980s (Carnes, 2000; Hewitt, 1999; Hewitt \& Arrowood, 1994). This interviewing technique has gained popularity in recent years. Systematic touch survey has been developed to screen possible CSA and Hewitt (1999) avows that it is based on the idea that touches fall along a continuum, ranging from good to neutral to bad. Rapholo (2018) states that Touch Survey in particular screens for possible abuse in several areas, namely: physical abuse, which is, screened looking at spanking, hitting or pinching; sexual abuse by asking about genital touches and lastly emotional abuse or neglect by asking about hugging and kissing. To this point, it is imperative during CSA allegations to screen for multiple forms of abuse since abuse does not occur in isolation.

The use of Touch Survey is effective for children who have self-representation skills as they are exposed to drawings according to Hewitt (1999), as a representation of themselves. To this point, Hewitt recommends that due to children's lack of self-representation skills, the Touch Survey should be used when assessing children of the age of four (4) years and above. Cronch et al. (2006) state that in the usage of Touch Survey, children are given warm up exercises wherein they review different feelings and faces associated with each. The aim is to assess children's self-representational skills, to establish rapport and subsequently assess their attention span. Touch Survey involves exposing children to different touches, namely; hugging, kissing, hitting, sexual touches and feelings associated with touches, location of their body where they have received the touch and by whom (Cronch et al., 2006; Rapholo,2018). Rapholo has established from his study in South Africa that the age and culture of the child have implications during the use of Touch Survey. For example, in his study, some forensic social workers have mentioned that Touch Survey works is most effective when assessing a child from urban areas unlike those in the rural areas as those who are in the cities are more westernised. Other forensic social workers postulated that in some cultures, mostly in the rural areas, it is a taboo for a boy to kiss his father, whereas in the western culture this is viewed as an expression of love. These forensic social workers stated that there is more disclosure rate when interviewing children from urban areas than rural areas by using the Touch Survey. To overcome all these challenges, Cronch et al. (2006) suggest that Touch Survey be used in combination with other empirically supported interviewing techniques. The writers are of the view that this technique should only be used in the instances where the child did not at all disclose possibility of sexual abuse. It is used as the last resort if other technique did not work out. It can be concluded that the Touch Survey appears to more accurate to bring about more disclosure of CSA.

\subsection{Anatomically Detailed dolls}

Anatomically detailed dolls according to Cronch et al. (2006) are the most controversial techniques discussed in the literature. Dolls are the most excellent communication and/or clarification tool if used properly (APSAC, 1997). They are only used where there is the disclosure of possible CSA (Faller, 2007; Kuehnle \& Connell, 2009; Rapholo, 2018). Faller (2007) and Spies (2006) avers that anatomically detailed dolls can be used to clarify the child's previous statements about sexual abuse rather than only relying on the child's statements. Professionals who use anatomical dolls should receive intensive training. The followings guidelines according to Faller (2007) and Holmes (2000) are mostly appropriate when using anatomical detailed dolls during forensic interviews:

- They should not be used when interviewing a child below the age of four years due to the suggestibility and children's lack of self-representation skills, as they require specific cognitive capabilities;

- They must only be introduced if the child has revealed possible sexual abuse;

- The interviewer should inform the child that dolls are not toys meant to play with;

- Dolls should be fully clothed prior to the usage;

- The interviewer should firstly assess the relevance of using the anatomical dolls;

- The interviewer must assess if the child is able to make representational shift prior to the usage of the dolls (Spies, 2006);

- The victim child should not be told whom the doll represent (Spies, 2006);

- The interviewer should not make assumptions about the child's demonstrations on the anatomical dolls;

- The interviewer should not force children to use the dolls in demonstrations;

- The dolls should only be used to a child whose language skills are limited or who is reluctant to talk, as a 
medium for clarifying verbal statements or a way of corroborating disclosure (Faller, 2007);

- If interviewing a White child, white dolls should be used, and if a Black child, then a black doll should also be presented to a child. Faller (2007) states that when conducting forensic interviews, the interviewer must assist the child choose dolls of the same number, age, race, and gender; and

- The interviewer should immediately after the exercise of anatomical dolls put them away from the child and avoid putting them laying before the child.

\subsection{Rapport Building}

Building rapport or working relationship with the client is fundamental to the helping professions. Wilson and Powell (2001) contend that rapport yields a strong element of trust between the interviewer and the child. Rapholo (2018) states that the interviewer should create an environment that is comfortable and be warm, listen attentively and ask developmentally sensitive questions. This contributes to building rapport with a child. In addition, the interviewer demeanour combined with a child friendly environment can assist in communicating that it is a safe place for the child (Cordisco-Steele, 2012).

Ground rules are vital during the rapport-building phase (Warren et al., 1999; Bull, 2003b; Wakefield, 2006; Jacobs et al., 2009; Shek \& Lin, 2015). The writers are of the view that the establishment of ground rules during forensic interviews make children relax. Children are sometimes anxious when they come for forensic assessment for the first time, more especially during pre-forensic interviews. The reasons to these is that for them the forensic social worker is a stranger as they are meeting him or her for the first time and that they do not know what is expected of them. Such children become confused, especially about the aim of the interviews (The New York State Children's Justice Task Force, 2003). They may even be afraid that they are in trouble. When children are relaxed, they are more likely to disclose possible sexual abuse if it had happened to them (Wilson \& Powell, 2001). Commencing with the meetings appropriately is indispensable since the first impression is established quickly and often have lasting effects on relationships (Chang et al., 2016; Jacobs et al., 2009; Lloyd et al., 2015).

\subsection{Free Call}

Free call technique is also very useful more especially during the pre-forensic interviews with the child. Children are more likely to accurately provide important details in what is termed free recall (Bruck et al., 2006; Spies, 2006). It was found in Rapholo's (2018) study that forensic social workers in South Africa engage children in free recall of the neutral events that they have experienced. One has given an example that she asks children to tell about their school holidays. The interviewer can then get further information through specific questions about the event. Interviewers should allow the child to provide a free narrative account in any order that the child wishes (e.g. Tell me about your school holidays); and "Tell me more" (Aldridge \& Cameron, 1999; Home Office, 1992; Spies, 2006). The purpose of this is for the child to be invigorated to give an account of the pertinent events in his/her own words and at his/her own pace. During the free call of events, Aldridge and Cameron (1999), Orbach et al. (2000), and Wood and Garven (2000) advice that the interviewer should not interject the narrative with questions.

To invite free narration of the events, (Bull, 2003a:3; Fouche, 2007:; Starks \& Samuel, 2002a; Aldridge \& Wood, 1998) recommend the following questions:

- "Did anyone tell you why you are coming to see me today?" or

- "Why do you think you are here today?"

Children during the free narration of neutral events are more likely to disclose sexual abuse by summarizing it, e.g.: "He did naughty things with me," which the interviewer would follow up with questions like:

- "Please tell me everything that happened"

\subsection{House and Community Plan}

This technique originated from techniques like genograms and eco-cards (Butler \& Karp, 1996; Fouché, 2007; Kaduson \& Schaefer, 1997; Perry \& Wrightman, 1991; Spies, 2006). Fouché and Joubert (2003) postulate that the house and community plan focuses is on the child's daily movements from his/her household to other secure or threatened places. The house and community plan technique is most useful during the pre-forensic interviews. Children are more likely to disclose possible sexual abuse through the use of this technique. It helps the child to identify the places where s/he feels secure and those in which $\mathrm{s} / \mathrm{he}$ feels threatened. The interviewer works together with the child by drawing a plan of child's household inclusive of its furniture. Thereafter, both the child and they then make clay models that represent family members. The areas such as the houses near the child's household and the places which s/he pays visit to most often, are also drawn. Exploration of boundaries also takes place in the 
process. The interviewer explores on the daily movements and routines of the child. Before the child is instructed to identify and mark all safe havens with a green pen and unsafe havens with a red pen, the interviewer firstly, establishes from the child if $\mathrm{s} / \mathrm{he}$ understands the difference between "safe" and "unsafe" by testing that with a neutral topic (Fouché, 2006; Fouché, 2007; Spies, 2006). The interviewer should then explore both the safe and unsafe ticks. If the child can disclose the possibility of sexual abuse, abuse-focused questioning (Cronch et al., 2006) should take place. Spies indicates that this approach can be used even in the egg technique which will be discussed below.

\subsection{The Egg Technique}

The egg technique is also highly recommended to be used during pre-forensic interviews. It helps children to be aware of their own personal boundaries and enables them to identify when someone intrudes on them (Spies, 2006) The interviewer exposes the child to a picture of the shape of an egg that the child has to complete by connecting the dotted outline around the figure and by colouring the personal space inside the dots (Rapholo, 2018). This enables the child to conceptualize the boundaries. During the application of this technique, the interviewer asks the child which of the people s/he would allow them inside the egg and those whom $\mathrm{s} / \mathrm{he}$ does not allow as well. The interviewer then explores every answer that the child gives. By so doing, forensic social workers in South Africa from Rapholo's (2018) study asserted that children are more likely to disclose possible sexual abuse. The writers therefore, advise that interviewers ask more abuse focused open-ended questions when taking children through this technique.

\subsection{The Robot}

This technique is most effective in the South African context as children are exposed to the three colours of a robot. Forensic Social Workers in South Africa use it during pre-forensic interviews to explore possible CSA (Fouché \& Joubert, 2003; Spies, 2006; Rapholo, 2018). Spies (2012) avers that the forensic interviewer should introduce children to the three touches as follows; the first touch is a bad touch (it involves being hurt); secondly is a secret touch (genitals are touched); and the third one is a good touch (positive contact). These types of touches are explained during the forensic interviews by being compared to a traffic light [also known as a robot in South Africa] (Fouché \& Joubert, 2003; Fouché, 2007; Spies, 2006). The red light (stop) symbolizes a bad touch, the orange light a secret touch (careful/ be aware) and the green light a nice touch (go ahead). Fouché (2007) states that the interviewer during the application of the robot technique, engages the child on the functions of different lights of the robot and that human beings also have also have robot in their bodies which cannot be seen with naked eyes, but can only be felt in their hearts. The interviewer will then explain to the child that the body of a person react to certain touching and that a light goes on in his or her body. For instance, if one hurts the other, the red light goes on, illustrating, "Stop". If none does not hurt the other and they are nice to us, then the green light goes on, and lastly, If one touches us on our bodies and if we feel not comfortable with that, or are not sure whether it is right or wrong, or when we are being asked to keep what someone did to us as a secret, the orange light goes on. The interviewer requests the child to place the clay balls that were used in the family graphic design on the appropriate colours of the traffic light. Thereafter, the interviewer will clarify and explore each clay on the relevant colours of the traffic light. If the child discloses sexual abuse, the interviewer should the follow forensic interviewing techniques such as abuse-focused questioning.

\section{Implications for Practice}

In the light of the above literature review on forensic interviewing techniques, the following should be taken into consideration during forensic interviews for CSA allegations:

- Social workers who conduct forensic interviews should possess an intensive specialised training on forensic interviewing during CSA allegations.

- The child should preferably be interviewed by the forensic social worker who has an understanding of child's cultural background.

- The age of the child should be assessed from the first contact with the child so as to establish which technique to apply between blind allegation interviews and informed allegation interviews.

- Blind allegation interviews are highly recommended to help the forensic social worker to be at a neutral stance, non-judgemental, objective and unbiased.

- The forensic interviewer should always starts the interviews with the pre-forensic interviewing techniques, to make children relax. Literature shows that most children are more likely to disclose possible sexual abuse at this stage. Then, forensic interviews can be used for clarification purposes. 
- The linguistic skills of the child should be assessed during the pre-forensic interviews.

- The forensic social worker should assess the child's ability to differentiate between the truth and a lie during the pre-forensic interviewing stage.

- Forensic interviews should be conducted in an environment which is child user-friendly.

- The forensic social worker should assess the age and/or the developmental level of the child prior to the selection of an appropriate interviewing technique.

- The forensic social worker should at all times (all sessions with the victim child) establish a good working relationship with the child under assessment.

- Anatomical dolls should be used with caution, and be avoided with very young children.

\section{Competing Interests Statement}

The authors declare that there are no competing or potential conflicts of interest.

\section{References}

Aldridge, J., \& Cameron, S. (1999). Interviewing child witnesses: Questioning techniques and the role of training. Applied Developmental Science, 3(2), 136-147. https://doi.org/10.1207/s1532480xads0302_7

Aldridge, M., \& Wood, J. (1998). Interviewing children. A Guide for child care and forensic practitioners. West Sussex: John Wiley and Sons Ltd.

Aldridge, N. C. (1999). Enhancing children's memory through cognitive interviewing: An assessment technique for social work practice. Child and Adolescent Social Work Journal, 16(2), 101-126. https://doi.org/10.1023/A:1022309423642

American Professional Society on the Abuse of Children. (2002). Practice guidelines: Investigative interviewing in cases of alleged child abuse.

American Professional Society on the Abuse of Children. (2012). Practice guidelines: Forensic interviewing in cases of suspected child abuse. Oklahoma City, OK: APSAC.

Bruck, M., \& Ceci, S. J. (1995). Amicus brief for the case of state of New Jersey v. Michaels presented by Committee of Concerned Social Scientists, Psychology, Public Policy, and Law 1 (pp. 272-322). https://doi.org/10.1037/1076-8971.1.2.272

Bruck, M., Ceci, S. J., \& Principe, G. (2006). The child and the law. (In Damon, W. \& Lerner, R.M., eds. Handbook of child psychology (6th ed.). USA: John Wiley \& Sons Inc. https://doi.org/10.1002/9780470147658.chpsy0419

Bull, R. (2003a). Good practice in child interviewing. Paper presented at the fourth Annual National Conference Towards Multidisciplinary Expertise in Handling Child Abuse. SAPSAC Conference Paper nr, 1. May, 13-15. Pretoria.

Butler, T. L., \& Karp, C. L. (1996). Activity book for treatment strategies for abused children. USA: SAGE Publications.

Carnes, C. N. (2000). Forensic evaluation of children when sexual abuse is suspected.

Chang, V., Decker, C., \& Scott, S. (2016). Developing helping skills: A step by step approach to competecy (3rd ed.). USA: Cangage Learning publishers.

Connell, M. (2009). The child advocacy center model. In Kuehnle, K. \& Connell, M., (Eds.) The evaluation of child sexual abuse allegations: A comprehensive guide to assessment and testimony (pp. 451-487). Hoboken, N.J: Wiley-Blackwell.

Cordisco-Steele, L. C. (2012). The forensic interview: a challenging conversation. In Goodyear-Brown, P. Handbook of child sexual abuse: identification, assessment and treatment (pp. 99-119). Hoboken, N.J: Wiley. https://doi.org/10.1002/9781118094822.ch5

Craig, R. A., Scheibe, R., Raskin, D. C., Kircher, J. C., \& Dodd, D. H. (1999). Interviewer questions and content analysis of children's statements of sexual abuse. Applied Developmental Science, 3(2), 77-85. https://doi.org/10.1207/s1532480xads0302_2

Cronch, L. E., Viljoen, J. L. \& Hansen, D. J. (2006). Forensic interviewing in child sexual abuse cases: Current techniques and future directions. Aggression and Violent Behavior, 11(3), 195-207. 
https://doi.org/10.1016/j.avb.2005.07.009

Davies, G. M., Westcott, H. L. \& Horan, N. (2000). The impact of questioning style on the content of investigative interviews with suspected child sexual abuse victims. Psychology, Crime, and Law, 6, 81-97. https://doi.org/10.1080/10683160008410834

Faller, K. (1993). Child sexual abuse: Intervention and treatment issues. Washington, D.C, WA: Department of Health and Human Services. https://doi.org/10.1037/e624552007-001

Faller, K. C. (2003). Understanding and assessing child sexual maltreatment (2nd ed.). London: Sage publishers

Faller, K. C. (2007). Interviewing children about sexual abuse. Controversies and best practice. Oxford: Oxford University Press. https://doi.org/10.1093/acprof:oso/9780195311778.001.0001

Ferrara, F. F. (2002). Childhood sexual abuse: development effects across the lifespan. USA: Wadsworth Publishers. https://doi.org/10.1016/S0145-2134(02)00345-9

Fouché, A., \& Joubert, J. M. C. (2003). Play techniques in the assessment of sexually abused black children. Acta Criminologica, 16(4), 12-20.

Fouché, A. (2006). Assessment of the sexually abused child. In Spies, G. M. (ed.), Sexual abuse dynamics, assessment and healing (pp. 205-239). Pretoria: Van Schaik.).

Fouche, A. (2007). Facilitating disclosure of child sexual abuse victims in the middle childhood: A forensic interview protocol for social workers (Doctoral dissertation). University of Pretoria: Pretoria.

Franklin, C., \& Jordan, C. (1999). Family practice in today's practice contexts. (In Franklin, C. \& Jordan, C., ed. Family practice-brief systems methods for social work. USA: Brooks/Cole publishing company. https://doi.org/10.1093/fampra/16.3.216

Hayes, B. K., \& Delamothe, K. (1997). Cognitive interviewing procedures and suggestibility in children's recall. Journal of Applied Psychology, 82, 562-577. https://doi.org/10.1037/0021-9010.82.4.562

Hershkowitz, I. (2001). Children's responses to open-ended utterances in investigative interviews. Legal and Criminological Psychology, 6, 49-63. https://doi.org/10.1348/135532501168190

Hershkowitz, I., Orbach, Y., Lamb, M., Sternberg, K. J., \& Horowitz, D. (2006). Dynamics of forensic interviews with suspected abuse victims who do not disclose abuse. Child abuse and Neglect, 30(7), 753-769. https://doi.org/10.1016/j.chiabu.2005.10.016

Hewitt, S. K., \& Arrowood, A. A. (1994). Systematic touch exploration as a screening procedure for child abuse: A pilot study. Journal of Child Sexual Abuse, 3, 31-43. https://doi.org/10.1300/J070v03n02_03

Hewitt, S. K. (1999). Assessing allegations of sexual abuse in preschool children: Understanding small voices (No. 22). Thousand Oaks, Sage publishers: Online publications

Holliday, R. E. (2003). Reducing misinformation effects in children with cognitive interviews: Dissociating recollection and familiarity. Child Development, 74(3), 728-751. https://doi.org/10.1111/1467-8624.00565

Holmes, L. S. (2000). Using anatomical dolls in child sexual abuse forensic interviews. American Prosecutors Research Institute Update Update, 13

Home Office. (1992). Memorandum of good practice. London: HMSO.

Huffman, M. L., Warren, A. R., \& Larson, S. M. (1999). Discussing truth and lies in interviews with children: Whether, why, and how? Applied Developmental Science, 3(1999), 6-15. https://doi.org/10.1207/s1532480xads0301_2

Jacobs, E. E., Masson, R. L., \& Harvill, R. L. (2009). Group counselling: strategies and skills. Asian Journal of Humanities and Social Studies, 3(4), 6.

Kaduson, H. G., \& Schaefer, C. E. (1997). 101 favourite play therapy techniques. London: Jason Aronson.

Kaliski, S. (2006). Psycholegal assessment in South Africa. Oxford: Oxford University Press Southern Africa.

Klein, K. (2010). The reality of child sexual abuse: A critique of the arguments used by adult-child sex advocates. CMC, Senior Theses. Paper 53. http://scholarship.claremont.edu/ $\mathrm{cmc}$ theses/53

Kuehnle, K. (1996). Assessing allegations of child sexual abuse. Sarasota: Professional Resource Exchange.

Kuehnle, K., \& Connell, M. (2009). The evaluation of child sexual abuse allegations: A comprehensive guide to assessment and testimony. Hobo Hoboken, N.J.: Wiley. 
Lamb, M. E., Sternberg, K. J., \& Esplin, P. W. (2000). Effects of age delay on the amount of information provided by alleged sex abuse victims in investigated interviews. Child Development, 71(6),1586-1596. https://doi.org/10.1111/1467-8624.00250

Lloyd, S., Schmidt, U., Khondoker, M., \& Tchanturia, K. (2015). Can psychological interventions reduce perfectionism? A systematic review and meta-analysis. Behavioural and Cognitive Psychotherapy, 43(6), 705-731. https://doi.org/10.1017/S1352465814000162

Müller, K. (2001). Clinical and forensic interviews and the child witness. Child Abuse and Research in South Africa, 2(2), 8-14.

Orbach, Y., Hershkowitz, I., Lamb, M. E., Sternberg, K. J., Esplin, P. W., \& Horowitz, D. (2000). Assessing the value of structured protocols for forensic interviews of alleged child abuse victims. Child Abuse and Neglect, 19(6), 733-755. https://doi.org/10.1016/S0145-2134(00)00137-X

Payne, M. (2005). Modern social work theory (3rd ed). Chigago. Oxford University Press

Perry, N. W., \& Wrightman, L. S. (1991). The child witness: Legal issues and dilemmas. USA: SAGE Publications.

Poole, D. A., \& Lamb, M. E. (1998). Investigative interviews of children: A guide for helping professionals. American Psychological Association. https://doi.org/10.1037/10301-000

Rapholo, S. F. (2018). Effectiveness of interviewing techniques with the Black child during forensic social work assessments: a South African perspective (Doctoral Thesis). University of Limpopo, South Africa

Saywitz, K. J., \& Comparo, L. B. (2009). Contemporary child forensic interviewing: evolving consensus and innovation over 25 years. (In Bottoms, B. L., Najdowski, C. J. \& Goodman, G. S. (Eds.), Children as victims, witnesses, and offenders: psychological science and the law (p. 102-127). New York: Guilford Press.

Saywitz, K. J., Goodman, G. S., \& Lyon, T. D. (2002). Interviewing children in and out of court: Current research and practice implications. In J. E. B. Myers, L. Berliner, J. Briere, C. T. Hendrix, C. Jenny, \& T. A. Reid, (Eds.), Th e APSAC handbook on child maltreatment (2nd ed., pp. 329-347), Sage Publications, Inc., Th ousand Oaks, CA (2002).

Shek, D. T., \& Lin, L. (2015). Core beliefs in the service leadership model proposed by the Hong Kong Institute of Service Leadership and Management. International Journal on Disability and Human Development, 14(3), 233-242. https://doi.org/10.1515/ijdhd-2015-0404

Smith, P. K., Cowie, H., \& Blades, M. (2003). Understanding children's development (4th ed.). Malden, Mass.: Blackwell. https://doi.org/10.1046/j.1467-8624.2003.00633.x

Smith, S. (2014). A forensic assessment model for the sexually abused child in the South African context (Doctoral dissertation). North-West University: Potchefstroom Campus, South Africa.

South Africa. (2017/2018). South African Police Service. Crime statistics overview RSA 2017/2018.

South Africa. (1977). The criminal procedure Act 55 of 1977. Pretoria: Government Printers.

Spies, G. M. (2006a). Substitute care for the sexually abused child (In Spies, G.M. Sexual abuse: Dynamics, assessment \& healing. Pretoria: van Schaik. p. 267-278).

Spies, G. M. (2012). Sexual abuse: Dynamics, assessments \& healing. Pretoria: Van Schaik.

Starks, J., \& Samuel, S. (2002a). A child-centered multi-disciplinary introduction to child sexual abuse. Paper presented at the 3rd Annual national conference towards multidisciplinary expertise in handling child abuse SAPSAC Conference Paper $n r$. 2. May, 14-16. Pretoria.

Talwar, V., Lee, K., Bala, N., \& Cronch, R. C. L. (2002). Children's conceptual knowledge of lying and its relation to their actual behaviours: Implications for court competence examines. Law and Human Behavior, 26(4), 395-415. https://doi.org/10.1023/A:1016379104959

Visser, M., \& Moleko, A. (2012). Community Psychology in South Africa (2nd ed.). Pretoria: Van Schaik.

Wakefield, H. (2006). Guidelines on Investigatory Interviewing of Children: What is the Consensus in the Scientific Community? IPT Library Resources. Retrieved July 6, 2016, from http:/www.ipt-forensics.com/library/ajfp1.htm

Warren, A. R., Woodall, C. E., Thomas, M., Nunno, M., Keeney, J. M., Larson, M., \& Stadfeld, J. A. (1999). Assessing the effectiveness of a training program for interviewing child witnesses. Applied Developmental 
Science, 3(2), 128-135. https://doi.org/10.1207/s1532480xads0302_6

Weyers, M. L. (2011). The Theory and Practice of Community Work: A Southern African Perspective (2nd ed.). Potchefstroom: Keurkopie

Wilson, J. C., \& Powell, M. (2001). A guide to interviewing children: essential skills for counsellors, police, lawyers and social workers. Oxon: Routledge. https://doi.org/10.1046/j.1365-2206.2002.t01-8-00258.x

Wood, J. M., \& Garven, S. (2000). How sexual abuse interviews go astray: Implications for prosecutors, police, and child protection services. Child Maltreatment, 5(2), 109-118. https://doi.org/10.1177/1077559500005002003

World Health Organization. (1999). Report of the consultation on Child abuse prevention. Geneva: W.

\section{Copyrights}

Copyright for this article is retained by the author(s), with first publication rights granted to the journal.

This is an open-access article distributed under the terms and conditions of the Creative Commons Attribution license (http://creativecommons.org/licenses/by/4.0/). 